\title{
Superovulation in mares: Limitations and perspectives
}

\author{
Marco A. Alvarenga, Marcio T. Carmo and Fernanda C. Landim-Alvarenga \\ Department of Animal Reproduction and Veterinary Radiology, FMVZ, Sao Paulo State University, UNESP- Botucatu, São Paulo, Brazil
}

\begin{abstract}
Summary
Superovulation is an important tool for routine use in equine embryo transfer (ET) in order to reduce the costs and to enhance the efficiency of ET programs. Satisfactory superovulatory answers (2-7 ovulations) have been reported in mares treated with Equine Pituitary Extract (EPE) and more recently using a commercial Equine FSH. However, embryo recovery rates have been inconsistent and below expectations (20$50 \%$ embryos/ovulation). Recent studies have shown that superovulatory treatment leads to disturbances in oocyte maturation and transport, especially in mares with a high ovarian response. Higher and more consistent embryo recovery rates per ovulation have been observed in mares treated with lower doses of EPE. This paper presents a review of recent studies related to superovulation in mares.
\end{abstract}

Keywords: superovulation, horse, oocyte maturation, embryo transfer, equine pituitary extract, equine FSH, reproduction

\section{Superovulation der Stute: Grenzen und Perspektiven}

Die Superovulation ist ein wichtiges Routinehilfsmittel im equinen Embryotransfer (ET), um Kosten zu reduzieren und die Effizienz von ET Programmen zu steigern. Bei der Stute wurden zufrieden stellende Resultate bei der Induktion einer Superovulation (2-7 Ovulationen) infolge der Behandlung mit equinem Hypophysenextrakt (EPE) und kürzlich auch durch das kommerziell erhältliche equine FSH (eFSH) erzielt. Trotzdem erwies sich die embryonale Wiedergewinnungsrate als sehr variabel und unter dem Erwartungswert (20-50\% Embryos/Ovulation). Verschiedene Studien haben gezeigt, dass eine induzierte Superovulation zu Störungen in der Reifung und im Transport der Oozyten führt, vor allem bei Stuten mit einem sehr guten ovariellen Response. Bessere und zuverlässigere Wiedergewinnungsraten pro Ovulation wurden durch die Verabreichung niedrigerer Mengen an EPE erzielt. Die vorliegende Arbeit liefert eine Übersicht zur induzierten Superovulation bei der Stute.

Schlüsselwörter: Superovulation, Stute, Oozytenreifung, Embryotransfer, equiner Hypophysenextrakt, equines FSH, Reproduktion

\section{Introduction}

The utilization of embryo transfer (ET) by the horse industry has increased extensively over the last 10 years. It is estimated by IETS (International Embryo Transfer Society) that around 25.000 ETs are performed yearly all around the world. USA, Brazil and Argentina are responsible for $80 \%$ of equine ET. In Europe the number of donor mares is constantly increasing every year. Until 2002, very few ETs had been performed in Germany, whereas currently an annual performance of around 500-600 equine ETs is estimated.

Superovulation is an important tool for routine use in equine embryo transfer in order to reduce costs and to enhance the efficiency of embryo transfer programs in this species. The impossibility to produce more than one embryo by donor per cycle is the most important factor for the low efficiency and the high costs of equine embryo transfer programs. Based on an embryo recovery rate per cycle of $60 \%$ and an expected pregnancy rate of $60 \%$ per ET it was possible to conclude that, in average, 3 cycles per embryo donor are necessary to have one pregnancy.

Increasing the number of ovulations per cycle is the only way to minimize this problem. The ideal protocol must describe a consistent method and be able to induce 3 ovulations per cycle, with the production of 2 embryos per flush. In consequence, this would guarantee one pregnancy in only one cycle.
Improvements in follicular response were shown in mares that were treated with more frequent daily injections of equine pituitary extract (EPE) or equine purified FSH. However, despite of a good superovulatory response, the embryo recovery rates were inconsistent and below expectations (Alvarenga et al. 2001, Niswender et al. 2003). Recent reports have shown that superovulatory treatment leads to disturbances in oocyte maturation and transport (Carmo et al. 2006, Carmo 2007) In the present paper we will summarize the results from recent papers and experiments related to superovulation in mares.

\section{Important factors that can interfere with the superovu- latory answer in mares}

The most traditional therapy used to induce multiple ovulations in mares is the administration of equine pituitary gonadotropins (EPE). EPE has been used for many years to induce multiple ovulations in mares and increase the embryo recovery rate from embryo transfer donor mares. Rates of 1 to 4 ovulations per mare and approximately 1 to 2 embryos per attempt have been published (Douglas 1979, Woods and Ginther 1984, McCue 1996).

An improvement in the superovulatory response was obtained with more frequent injections of EPE. In an experiment conducted at Colorado State University (Alvarenga et al. 2001) mares were given $25 \mathrm{mg}$ of EPE twice a day $(50 \mathrm{mg}$ total daily 
dose) which resulted in 7.1 ovulations per mare and 3.5 embryos per mare were collected, versus 2.4 ovulations and 1.5 embryos per mares that received injections once a day ( $25 \mathrm{mg}$ total daily dose). However, the embryo recovery rates per ovulation were significantly lower (49\% vs. 60\%) in mares treated twice daily. It was also observed that as the number of ovulations increased the percentage of recovered embryos tended to decrease, particularly in mares with a large number of ovulations. In a subsequent experiment (Scoginn et al. 2002) a higher superovulatory answer was also observed using $25 \mathrm{mg}$ of EPE twice daily when compared with $12.5 \mathrm{mg}$ injected twice daily (4.7 vs. 3.4 ovulations, respectively). However, the embryo recovery was higher for mares treated with the lower doses of EPE (12.5 mg).

In our laboratory the use of $25 \mathrm{mg}$ of EPE twice daily has consistently resulted in ovulation rates between 4 to 5 follicles/mare with an embryo recovery rate per ovulation between 30 to $40 \%$.

Since 2003 equine follicle stimulating hormone (eFSH) is commercially available, consequently just few and recent experiments have been conducted using eFSH to superovulate $(\mathrm{SO})$ mares. Some experiments were conducted by Colorado State University to evaluate the efficacy of a commercially available purified eFSH (Bioniche Animal Health USA) in inducing superovulation in cycling mares. In the first experiment (Niswender et al. 2003) using this product, mares were treated with 12.5 or $25 \mathrm{mg}$ of eFSH twice daily beginning 5 or 6 days after ovulation. Mares treated with $12.5 \mathrm{mg}$ of eFSH twice daily and either hCG (G1) or deslorelin (G2) to induce ovulations developed more pre-ovulatory follicles than untreated controls $(3.4$ (G1) vs. 3.8 (G2) vs. 1.1 (control group) ovulations). In this study mares receiving a higher dose (25 mg twice daily) of eFSH followed by hCG had a higher number of pre-ovulatory follicles (6.7 follicles), however only $50 \%$ of these follicles ovulated. The embryo development rate per ovulation, observed with 14 days of pregnancy, was lower in mares treated with $25 \mathrm{mg}$ of eFSH (18\%) when compared with those given $12.5 \mathrm{mg}$ of eFSH $\mathrm{f}(52 \%)$.

In 2003 (Machado et al. 2004), an experiment was conducted in our laboratory to compare the efficiency of EPE and eFSH in promoting superovulation in six crossbred mares. The mares were randomly divided into three groups: Group 1 (control), group 2 (EPE application - $25 \mathrm{mg}$ intra muscular (i.m.), twice daily), and group 3 (eFSH application - $12.5 \mathrm{mg}$ i.m., twice daily). The results showed that EPE and eFSH were able to promote superovulation in mares (3.4 (EPE) vs. 4.2 (eFSH) ovulations/mare) and improved the number of embryos recovered (1.0 (EPE) vs. 2.2 (eFSH) embryos/mare), when compared to the control group $(0.4 \mathrm{embryos} / \mathrm{mare})$. Although no statistical differences were observed, the embryo recovery rate was numerically higher for mares treated with eFSH when compared with EPE (50\% vs. $30 \%$, respectively for eFSH and EPE).

In another experiment also performed with eFSH (Alvarenga et al. 2003), sixteen mares were used over two cycles. The number of ovulations during the cycle in which mares were treated with eFSH (4.0 ovulations) was significantly higher than the one observed in the control cycle (1.0 ovulation). One mare with 5 pre-ovulatory follicles did not ovulate after
eFSH treatment and consequently was not flushed. The average number of embryos recovered per mare from the eFSH cycle (2.0 embryos/ cycle) was significantly higher than the number of embryos recovered from the control cycle 10.6 embryos/cycle).

However, in two recent publications poor superovulatory answer and embryo production were reported in mares treated with $12.5 \mathrm{mg}$ of eFSH twice daily. In one of these experiments Raz et al. (2006) observed that the mean number of ovulations was 2.2 and 1.1 for treated and control mares, respectively. The percentage of embryos recovered per ovulation was around $30 \%$ in eFSH treated mares and $60 \%$ in control mares. Injecting $12.5 \mathrm{mg}$ of eFSH, Squires et al. (2006) obtained on average 3.5 ovulations and 1.5 embryos in mares considered "good" donors and 2.3 ovulations and less than 1.5 embryos in mares considered "poor" donors. Also Peres et al. (2007) observed a good superovulatory response (5.6 ovulations) with a low percentage of embryos per ovulation (30\%) in transitional mares superovulated with equine $\mathrm{FSH}$.

\section{Disturbances induced by superovulation in follicle and oocyte maturation}

It is well known that superovulation induces several alterations on oocyte maturation in cows. Several papers have shown that 30 to $40 \%$ of the cows did not respond to SO treatments and that about 40 to $50 \%$ of produced embryos were not transferable. Consequently a high percentage of recovery structures from superovulated cows are not suitable to be transferred, because of morphological alterations and/or presence of no fertilized structures (Monniaux et al. 1983).

Few experiments were conducted to determine the reasons for low embryo recovery rates in superovulated mares. A recent experiment verified the effect of EPE treatment administered twice daily on the transport of the oocytes into the oviduct and on the cytoplasmatic and nuclear oocyte maturation (Carmo 2007). In this study, 22 mares aging from 3 to 12 years were used $(9$ control mares, 13 EPE treated mares). These mares were monitored twice daily by ultrasound until the presence of a follicle $>35 \mathrm{~mm}$ in diameter. The superovulatory protocol consisted of $25 \mathrm{mg}$ of EPE twice a day, starting at day 7 post-ovulation. Mares were submitted to slaughter 12 to 24 hours after detection of the first ovulation. The oviducts were then removed from the ovaries and uterus, dissected and flushed with PBS. It was observed that the mean number of ovulations/mare and the percentage of viable oocytes/ovulation recovered from the oviduct was 1.22 and $90 \%$ for control animals and 4.77 and $64 \%$ for superovulated mares, respectively. In mares presenting less than 4 ovulations the rate of oocytes recovered/ovulation was similar between treated and control animals. A large blood coagulum was observed at the ovulation fossa in most of superovulated mares, which was not present in the control group. The decrease in the percentage of oocytes recovered per ovulation was similar to the decrease in the embryo recovery per ovulation reported by others in mares superovulated with the same EPE dose as used in this experiment (Alvarenga et al. 2001). 
Based on the results from these experiments it was possible to conclude that the exacerbated number of ovulations observed in EPE treated mares alter the mechanism of oocyte transport to the oviduct. Also, an obstruction of the ovulation fossa by the coagulum could somehow impair the oocyte migration into the oviduct. In addition, the superovulatory treatment seems to lead to several modifications in the follicular environment and to alter oocyte maturation. The combination of all these disturbances certainly is the cause of the low and variable embryo recovery rate observed in superovulated mares.

\section{New protocols using low doses of EPE and equine FSH}

Based on the observation that the lower the number of ovulation after superovulatory treatment the higher the embryo recovery rate per ovulation, an experiment (Rocha Filho 2004) was designed to evaluate the effects of low doses of EPE and purified eFSH on follicular growth, ovulation rate and embryo recovery rate in mares. After an embryo collection attempt on day 8 post-ovulation (control cycle), all mares received an injection of prostaglandin and were assigned to one of two experimental groups: EPE $(n=13)$ or eFSH $(n=14)$.

Treatments consisted of administration of EPE (4 mg i.m., single daily injection (s.i.d.); group EPE) or eFSH (5 mg i.m., s.i.d.; group eFSH) from day 8 (day $0=$ ovulation) until the day of the induction of ovulation with hCG. The percentage of mares with more than one ovulation tended to be higher in the EPE-treated cycle than in the control cycle $(30.8 \%$ vs. $0 \%$, respectively). Although the mean number of ovulations was similar between the EPE-treated cycle and control cycle, (1.2 and 0.9 , respectively), the mean number of recovered embryos was higher in the EPE treated cycle (1.1 vs. 0.6). The eFSH treatment produced a higher incidence of multiple ovulations (50\% vs. $0 \%$ ) and an increased mean number of ovulations (1.6 vs. 1.0) compared to the control cycle, both treatments provided the recovery of at least one embryo/ flush.

Based on the low number of mares responding to the $4 \mathrm{mg}$ dose of EPE injected once daily in this experiment, another experiment was designed with an increased dose and frequency of administration of EPE $(7 \mathrm{mg}$ of EPE injected twice daily). Currently, with the utilization of this protocol 2 ovulations per cycle and 1.3 embryos per flush (Alvarenga et al. unpublished data) have been consistently obtained. The protocol guaranteed one embryo per flushing, even when used on subsequent estrus cycles during the breeding season.

The use of this low dose protocol (7 mg of EPE twice daily) on the last breeding season in a private ET Center in Brazil over 58 cycles in 34 mares, resulted in 1.7 ovulations/cycle and 1.15 embryos per flush. A total of 67 embryos were recovered. These are twice as many embryos as expected in mares with single ovulations. Since considering an embryo recovery rate of $60 \%$, about 35 embryos in single ovulation cycles were expected in 58 cycles.

Despite other published experiments showing little or no effect of porcine FSH (pFSH) on mares (Squires et al. 1986), a recent publication (Krekeler et al. 2006) showed that a small dose of pFSH was able to consistently induce double ovulations in mares. In this experiment few mares were used (two thoroughbreds and three warmblood mares) and each mare was treated with two dose regimes of $\mathrm{pFSH}$ during consecutive cycles. Six days after ovulation, each mare was treated twice daily with injections of either $10 \mathrm{mg}$ or $25 \mathrm{mg}$ of $\mathrm{pFSH}$ (Folltropin-V; Bioniche, USA). In both regimes, mares showed an average of 2.2 ovulations per cycle and had more ovulations during treated cycles than during control cycles (1.1 vs. 0.6 embryos per cycle, respectively). The dose of pFSH had no effect on the number of ovulations per cycle, but fewer embryos/cycle were recovered from mares that received the lower dose (10mg) of pFSH (1.32 vs. 0.57). In contrast, in a very recent study from our laboratory using the same $\mathrm{pFSH}$ protocol (10 mg twice daily) in 20 cycles from Quarter Horse and Mangalarga mares (Alvarenga et al. unpublished data) no increase of ovulation rates was observed. The reasons for the controversial results between these experiments are not clear and must be investigated.

\section{Final Conclusions}

Despite of all efforts to improve the efficiency of superstimulatory treatments there is still a lack of a consistent and repeatable superovulatory treatment for mares. The reasons for this lack certainly are related to disturbances induced by superovulatory treatments. The observation that embryo recovery rates per ovulation is higher in mares with 3 or less ovulations indicates that the utilization of a low dose of EPE or eFSH, aiming to have a smaller ovarian answer, seems to be the best way to improve the number of produced embryos in equine embryo transfer programs.

\section{References}

Alvarenga M. A., McCue P. M., Bruemmer J., Neves Neto J. and Squires E. L. (2001) Ovarian superstimulatory response and embryo production in mares treated with equine pituitary extract twice daily. Theriogenology 56, 879-887

Alvarenga M. A., Squires E. L., Machado M. S., Arantes M., Peres K. R., Leao K. M., Oliveira J. V. and Roser J. F. (2003) Evaluation of superovulatory answer in mares treated with purified equine $\mathrm{FSH}$. Acta Scientiae Veterinary 31, 216-217

Carmo M. T. (2007). Disturbs on oocyte transport and maturation of mares superovulated with Equine Pituitary Extract. 156p. PhD Thesis - Faculdade de Medicina Veterinária e Zootecnia, Universidade Estadual Paulista, Botucatu - Brazil

Carmo M. T. , Alvarenga M. A., Losinno L. and Aquilar J. J. (2006) Oocyte transport to the oviduct of superovulated mares. Animal Reprod. Science 94, 337-339

Douglas R. H. (1979). Review of induction of superovulation and embryo transfer in the equine. Theriogenology 1 1, 33-46

Krekeler N., Hollinshead F. K., Fortier L. A. and Volkmann D. H. (2006). Improved ovulation and embryo recovery rates in mares treated with porcine FSH. Theriogenology 66, 681-682

Machado M. S., Carmo M. T., Squires E. L., Roser J. F. and Alvarenga M. A. (2004) Follicular dynamic, superovulatory response and embryo recovery rates in mares treated with constant and decreasing doses of equine pituitary extract (EPE) and purified equine FSH. Hovemeyer Foundation Monographies Series No $14,75-76$

McCue P. M. (1996) Superovulation. In: Squires E.L. (Ed) The veterinary clinics of north america - equine practice: diagnostic techniques and assisted reproductive technology. W. B. Saunders, Philadelphia 1-11

Monniaux D., Chupin D. and Saumande J. (1983) Superovulatory responses of cattle. Theriogenology 19, 55-81 
Niswender K. D., Alvarenga M. A., McCue P. M., Hardy Q. P. and Squires E. L. (2003). Superovulation in cycling mares using equine follicle stimulating hormone (eFSH). J. Equine Vet. Sci. 23, 487-500

Peres K. R., Fernandes C. B., Alvarenga M. A. and Landim-Alvarenga F. C. (2007) Effect of eFSH on ovarian cyclicity and embryo production of mares in spring transitional phase. J. Equine Vet. Sci. 27, 176-180

Raz T., Corrigan M., Loomis P. and Card C. (2006). Effects of equine follicle stimulating hormone (eFSH) on pregnancy rate and embryo development in mares. Animal Reproduction Science 94, 400-402

Rocha Filho A. (2004) Effects of low doses of equine pituitary extract (EPE) and purified equine FSH (eFSH) on follicular growth, ovulation rate and embryo recovery rate in mares. Master Thesis $106 \mathrm{p}$. - Faculdade de Medicina Veterinária e Zootecnia, Universidade Estadual Paulista, Botucatu- Brazil

Scoggin C. F., Meira C., McCue P. M., Niswender K. D., Carnevalle E. M., Nett T. M. and Squires E. L. (2002). Strategies to improve the ovarian response to equine pituitary extract in cyclic mares. Theriogenology 58, 151-164
Squires E. L., Garcia R. H., Ginther O. J., Voss J. L. and Seidel G. E. (1986). Comparison of equine pituitary extract and follicle stimulating hormone for superovulating mares. Theriogenology 26 , $661-670$

Squires E. L., Logan N., Welch P. and McCue P. M. (2006) Factors affecting the response to administration of equine FSH. Animal Reproduction and Science 94, 408-410

Woods G. L. and Ginther O. J. (1984) Collection and transfer of multiple embryos in the mare. Theriogenology 21, 461-469

Prof. Marco Alvarenga,

Faculty of Veterinary Medicine-

Sao Paulo State University-UNESP

Botucatu-SP-186180-000

Brazil

malvarenga@fmvz.unesp.br 